\title{
Research on Transformation and Upgrading of the Traditional Physical Retail Enterprises in China
}

\author{
Ye Wang ${ }^{1, *}$, Liang $\mathrm{Wu}^{2}$ \\ ${ }^{1}$ School of Management, Xinhua College of Sun Yat-Sen University, Guangzhou, Guangdong 510520, China \\ ${ }^{2}$ School of Management, Xinhua College of Sun Yat-Sen University, Guangzhou, Guangdong 510520, China \\ * Corresponding author. Email: mdwy@xhsysu.edu.cn
}

\begin{abstract}
In recent years, the performance of Chinese brick-and-mortar retailers has been under constant pressure in the challenges of the e-commerce industry. We provide the comprehensive reviews of the theories of new retail. We synthesize research insights on the brick-and-mortar retailers' transformation and upgrading. We put forward the suggestions for accelerating the transformation and innovation of the brick-and-mortar retailers in China, which are from three aspects: management concepts, elements of new retail and operations management.
\end{abstract}

Keywords: physical retail enterprise, transformation, upgrading, new retail

\section{INTRODUCTION}

Since Jack Ma put forward the concept of "new retail" in 2016, JD.com, Suning and other enterprises have successively put forward the concepts of "boundless retail" and "smart retail". The industry has reached a consensus on the arrival of the era of retail reform, and the e-commerce enterprises have penetrated into the brick-and-mortar retail enterprises through investment and acquisition. The reason for this new trend is that the growth of online traffic is close to the "ceiling", while the offline retail market, although impacted by e-commerce, still has room for transformation and upgrading. The State Council of China issued the guidelines to promote the transformation of brick-andmortar retail in 2016. It pointed out that the physical retailing is an important basis for commodity circulation, an important carrier to expand consumption and an important way to the prosperity of the market. In recent years, with the upgrading of consumer demand, the physical retail format has been developing and innovating, and the physical retail scale has been further expanded. Many traditional retail enterprises continue to seek innovation and transformation in business model, category management, operation management and other aspects. The integration of online and offline development has made initial achievements in the new retail model. Some brick-and-mortar retail enterprises are still following the old road of physical store expansion, with the construction of virtual stores lagging behind, lack of experience in community marketing, and poor effect of hastily launched the live streaming. The new retail model of online and offline deep integration is one of the important paths for the transformation and upgrading of physical retail enterprises. The new retail theory needs to be further improved.

\section{RESEARCH REVIEW}

\subsection{Research on the New Retail Theory}

Before Jack Ma put forward the concept of new retail, Chinese academic circles had explored the retail model. According to Li Fei (2013), retail channel reform has gone through four stages: single channel, multi-channel, crosschannel and omni-channel. Omni-channel retail is actually omni-channel shopping for customers. ${ }^{[1]}$ After that, a number of scholars proposed the combination of retail and e-commerce to form an omni-channel retail integrating online and offline. The academic world began to conduct more comprehensive and in-depth research on new retail in 2017. Liang Yingying (2017) used the theory of "new retail wheel" to explain the emergence and development of new retail in China. Scholars like Du Ruiyun and Yan Zhanghua studied the concept, significance and trend of "new retail". ${ }^{[2]}$

\subsection{Research on the Transformation of Physical Retail}

With the deepening of the new retail research, the transformation of physical retail has also become one of the academic research topics. Gao Huisheng and Wang Chengmin (2020) applied the theory of dynamic capability to study the digital transformation of physical retail enterprises. ${ }^{[3]}$ Xuan Chaofeng and Gao Jing(2019) proposed the orientation of transformation of physical retail industry under the new development concept. ${ }^{[4]}$ Yang Jianzheng et al.(2018) used the SWOT tool to analyze the transformation of traditional retail enterprises, and proposed the choice of transformation paths from five aspects of business model elements. ${ }^{[5]}$ 
Liu Xiangdong et al.(2018) took Rainbow Shopping Mall as an example to study the process of digital transformation of brick-and-mortar retailers. ${ }^{[6]}$

\subsection{Research Gaps}

From the perspective of new retail research, most researches before 2017 focus on omni-channel retail and discuss the integration of online and offline development. After 2017, the industry led the academic community to carry out the research on the new retail. Scholars broke through the single perspective of omni-channel and studied consumer, supply chain, business model, big data analysis, marketing mode and other aspects. With the development of new retail research, the transformation of traditional retail enterprises has become a new research direction. Scholars use case studies, qualitative and quantitative studies and other research methods to explore the direction and path of transformation of brick-and-mortar retail enterprises.

On the basis of new retail, scholars have carried out some studies on the transformation of physical retail. Relevant literature is mainly analyzed from the perspective of digital transformation or business model, and case studies are conducted on successful enterprises in transformation. Relevant existing studies were carried out in a relatively stable static environment, without studying the misunderstandings and corresponding countermeasures existing in the transformation process of physical retail enterprises, or analyzing the reasons for unsuccessful enterprises in the transformation. The academic community needs to study the adaptability and crisis responses of physical retail enterprises in the rapidly changing and dynamic environment. From the perspective of enterprise practices, accelerating transformation and upgrading is the only way for physical retail enterprises to maintain vitality in a dynamic environment, and it is also the common demand of enterprise managers. Therefore, it is very necessary for brick-and-mortar retail enterprises to identify the countermeasures to accelerate the transformation and upgrading, so as to make preparations for the accelerated transformation and the recovery of consumer demand after 2020.

\section{MISUNDERSTANDING OF NEW RETAIL}

Only the transformation of innovation is the "true" transformation. This paper summarizes the misunderstanding of the transformation of brick-and-mortar retail enterprises as follows.

\subsection{New retail means expanding online sales channels}

The new retail is not a simple combination of retail and the Internet, neither is it equivalent to the $\mathrm{O} 2 \mathrm{O}$ model. From the perspective of academic research, scholars have not reached a consensus on the connotation of the "new retail". On the whole, the new retail includes shopping experience, digital technology-driven, omni-channel integration, integration of operations procedure, upgrading of supply chain and other elements. New retail is a deep integration and restructuring of the above elements. From the enterprise practice, many retail enterprises do not understand the true meaning of the new retail. They simply think that new retail means they set up the e-commerce departments, and equip with electronic merchants. Some brick-and-mortar retail enterprises think that increasing online shopping sales and undertaking network marketing are new retail. In fact, this is a big misunderstanding of new retail especially for managers. Wanda Group, as the largest shopping mall operator in China, set up the e-commerce platform "ffan.com" in 2014 But ffan.com has not occupied a space in the e-commerce market for many years. Therefore, the simple combination of brick-and-mortar retail and e-commerce doesn't mean the "new retail", and some brick-and-mortar retail enterprises do not catch the essence of new retail.

\subsection{The essence of new retail is higher sales}

Many physical retail enterprises still take the turnover as the main basis for performance evaluation. As a result, the offline retail department and the online retail department operate independently, and cross-departmental cooperation reduces the operating efficiency, so it is difficult to form synergy. According to Ali research institute, the new retail is a data-driven retail mode centered on consumer experience. It is essentially a transformation from "goods -- field -people" to "people -- goods -- field", which reflect the essence of consumer-centered. The essence of new retail is to create value for customers, not to sell goods, so enterprises need to consider the problem of transformation from this point of view. For retail enterprises, they should not only create value for customers based on shopping experience, but also continuously and effectively create value for customers, so as to improve customer perceived value. Brick-and-mortar retail enterprises should change their focus from sales performance to customer value, and from category management to customer demand, so as to improve customer perceived value.

\subsection{The transformation of physical retail enterprises is the application of digital technology}

Digital transformation refers to using advanced internet information technologies, such as big data and cloud computing, which enables enterprises to operate digitally and improve their management efficiency. But the digital transformation is a large and long-term return investment For enterprise performance it is difficult to have an immediate effect. This caused many physical retail enterprises to transform slowly, but some new retailers such 
as Fresh Hema realize the advantages of digital operations very quickly. Digitalization is only a technical means of transformation, which is essentially based on new equipment and new technology, and it is the necessary basis for innovation transformation. However, digital transformation is not the goal. Enterprises need to combine with other elements of transformation. They need to take innovation as the orientation and technology as the driving force, so as to realize the overall transformation of physical retail enterprises.

\section{PROPOSAL FOR INNOVATIVE TRANSFORMATION}

Under the situation of surging online consumer demand, resources were hastily organized to deal with the situation, with unsatisfactory results. Therefore, brick-and-mortar retail enterprises not only need to transform, but also need to accelerate the transformation guided by innovation. Combined with the above analysis, the transformation and upgrading can be improved from the following three aspects.

\subsection{Upgrade our concepts}

Due to the heavy burden of transformation, the lack of relevant professional talents and the lag in supporting resources, the physical retail enterprises are in a state of being reluctant to transform. In the early period of transformation, the input cost is too high, but the market effect is not proportional to the input, which hinders the transformation process of physical retail enterprises. Enterprise managers lack a deep understanding of new retail, omni-channel and other new ideas, which is bound to affect the implementation effect of transformation. The managers of brick-and-mortar retail enterprises need to improve their understanding of the new retail and reunderstand the new retail on the theoretical level so as to actively promote the transformation.

\subsubsection{Create a mindset of "new retail"}

The traditional physical retail enterprises expand the number of stores, which is emphasized on the scale of chain-store operations. But the new retail mode is more focused on the efficiency of resources integration and elements of reconstruction, and the transformation from traditional extensive management to consumer demand leading and information technology-driven. The managers of the physical retail enterprise need to consider the overall situation, break the inherent habitual thinking pattern of the industry, establish the thinking of new retail, pay attention to the top-level design. Managers should make clear that innovation and transformation is the only way for the longterm development of enterprises, adjust the organizational structure, set up an independent leading group for transformation, break down the original departmental barriers, and quickly map out the roadmap and timetable for transformation, so as to ensure efficient implementation.

\subsubsection{Create value for customers}

With the further popularization of the Internet, omnichannel buyers are generated.This new type of buyers will notice and choose multiple purchase channels at the same time, instead of choosing only one channel among multiple parallel channels as traditional buyers do. For example, when buying beauty products, female consumers may pay attention to the information from multiple online and offline channels, and choose the most appropriate channel after weighing and comparing. For consumers, the utility maximization of the purchase process is one of the reasons why they choose the purchase channel. Therefore, physical retail enterprises should be for the purpose of creating value for customers. They should explore the need of customers by big-data mining, and improve shopping experience through the online and offline stores, communicate with coustomers through new media such as Weibo and WeChat, promote the turnover through community marketing and influencer marketing.

\subsection{Upgrade Elements of New Retail}

As mentioned above, the meanings of new retail are very abundant, which have many elements: resources integration, restructure of consumer experience, information technology-driven, omni-channel buying, integration of business model, upgrading of supply chain and others. The factors are closely related to each other and influence each other. According to the Southern Urban Daily, the clothing brand "Gloria" has achieved an average daily turnover of more than 1 million yuan through the social operation of WeChat. Today, the need for integration among elements is more urgent, and the advantages of retailers that have been in rapid transformation in the past are highlighted. No matter how fast or slow the transformation was in the past, it is now facing the great impact. Accelerating the transformation is the common aspiration of all brick-andmortar retail enterprises. In addition to accelerating the upgrading of the concept, the transformation of the new retail model also needs to be accelerated at the business level.

\subsubsection{Relatively weak elements need to be upgraded at an accelerated pace}

Due to the differences in business development and enterprise scale, some elements of new retail in the process of transformation have developed rapidly, while others have developed slowly. The development of these elements is not balanced. According to a Nielsen survey, $67 \%$ of retailers plan to expand their online channels, accelerate the layout 
of their home business and their front positions, in terms of opportunities and strategic priorities for the retail industry in the coming year. 53\% said they would adjust the structure of their products, increase the stock of health, disinfection and protection products and expand the proportion of shelf space. $43 \%$ said they would deepen the supply chain, especially the fresh supply chain, and strengthen the relationship and communication efficiency with the brand owners. ${ }^{[7]}$ The survey results indicate that brick-and-mortar retailers expect to improve the uneven development of new retail elements. Therefore, the relatively weak elements need to be accelerated to deal with the future consumption recovery.

\subsubsection{Accelerate the deep integration of technology with other elements}

Demand is the motive power, and technology is the driving force. Digital technology is becoming more and more important in the transformation of physical retail enterprises. Technology is the lubricant of integration among the elements of the new retail, and it can promote the efficiency of resource allocation. However, technology is a tool, not a target. Technology enables enterprises to transform, and technology is deeply integrated with other factors to solve problems such as flexible supply chain, convenience of buying, users' profile and omni-channel retail through systematic solutions.

\subsection{Accelerate the upgrading of operation and management}

The operation and management of brick-and-mortar retail enterprises are facing challenges. The managers should not only speed up the upgrading of strategic concepts, but also speed up the upgrading of tactical strategies. They should implement the new retail concepts into enterprise operations, customer service and marketing strategies as soon as possible.

\subsubsection{Fully realize $O A O$ and $D 2 D$}

OAO refers to the "Online and Offline" operation mode. That means the omni-channel mode of organic integration of physical stores and Online stores. Retailers provide omni-channel consumption experience. Online consumers are led to offline brick-and-mortar stores for shopping experience. Meanwhile, VIP customers from offline brickand-mortar stores can also make purchases from online stores.

D2D means "Door to Door" . Door to door delivery service can improve customer satisfaction and loyalty. As a leading omni-channel retailer in China, Suning has always stick to developing the strategy of two-line integrated smart retail for many years, and has basically realized the operation mode of OAO. D2D has also achieved rapid growth.
According to the data provided by Sina, during the Spring Festival this year, the online supermarket business of Suning doubled, and the online orders of Carrefour increased by $300 \%$ year on year. Retail market provided an opportunity for Suning to realize the full coverage of community life services.

\subsubsection{Pay attention to online community marketing}

Physical retail enterprises fully realize only layout in advance can rapidly response. Those retailers who have had some experience of online community marketing can quickly adjust operation strategy. The sales quickly invite VIP customers to set up the WeChat group of shopping, they take advertising by short video platform to attract new customers, and improve the conversion rate of online traffic. Community operation is very important for small retailers such as clothing, beauty and fresh goods retailers. The efficiency of community operation determines the performance of pysical retail enterprises. Some small retailers need to pay more attention to community operation and improve customers' repurchase rate in the process of accelerating innovation and transformation.

For some big retailers such as hypermarkets, department stores and shopping malls, they need to further strengthen the importance of the consumption scene. Brick-and-mortar retailers need to consider accelerating the construction of a deeply integrated online and offline consumption scene, so as to meet consumers' diversified needs. The new generation of consumers under backgroud of mobile internet, who pursuit more personalized and diversified demands. They pay more attention to the shopping experience, collect product information on internet, choose the shopping place by the fragmented online information. Demands of consumers are triggered by shopping scene, short video and influencers. Retailers need to adjust strategies to accelerate the construction of consumption scenes.

\section{CONCLUSION}

The brick-and-mortar retail industry is faced with the opportunities and challenges of reform and development. Brick-and-mortar retailers should accelerate the innovative transformation from the three aspects: management concept, new retail elements and operations management

1) The managers of physical retail enterprises should update their ideas from the perspective of ideology, systematically understand and implement the new retail, and focus on transaction volume, customer value, shopping experience, so as to strengthen the determination of the transformation.

2) In order to realize accelerated transformation, the integration of various elements of the new retail mode should be realized first. As the transformation progress of various physical retailers varies, we can start with weak elements. 
3) At the operation management level, OAO and D2D should be implemented to improve the operation level.

4) Because of the different business types, the operation management will be completely different. For small retailers such as convenience stores and fresh goods retailers, community operation is very important, and for big retailers such as department stores, consumption scene construction is very critical.

\section{REFERENCES}

[1] Li F. (2013) The meaning, causes and countermeasures of omni-channel retail -- a discussion on the revolutionary storm of multichannel retail in China. Journal of Beijing Technology and Business University (social science edition), 2: 1-11.

[2] Liang Y. (2017) Research on the emergence and development of "new retail" in China based on the theory of "new retail wheel". Contemporary Economic Management, 9: 6-11.

[3] Gao H., Wang C. (2020) Analysis of digital transformation of physical retail enterprises based on dynamic capability theory. Journal of Commercial Economics, 1: 79-83.

[4] Xuan C., Gao J. (2019) Path and countermeasures for the transformation and upgrading of China's physical retail industry under the new development concept. Journal of Commercial Economics, 21: 172-175.

[5] Yang J., Qi P., Wang T. (2018) Research on the transformation and upgrading of traditional retail enterprises in China under the background of "new retail". Contemporary Economic Management, 9: 24-31.

[6] Liu X., Tang P. (2018) Practices and experiences in digital transformation from entity retailers in China: case study based on rainbow department store Co., Ltd. Journal of Beijing Technology and Business University (Social Sciences), 33: 12-21.

[7] Nielsen Co. (2020) China's retail industry is brewing changes and opportunities under COVID - 19 outbreak. http://finance.sina.com.cn/stock/relnews/us/2020-03-

05/doc-iimxxstf6599454.shtml 